\title{
Investigating the Impact of QSE Integration on Process Performances: An Empirical Study in Moroccan Companies
}

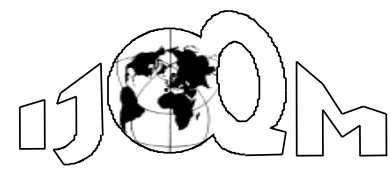

DOI: $10.46970 / 2020.26 .3 .4$

Volume 26, Number 3

September 2020, pp. 225-239

\author{
Fatima Bennouna \\ Driss Amegouz \\ Sidi Mohammed ben Abdallah University of Fes \\ (bennouna.ensa@gmail.com) \\ (amegouz@yahoo.fr) \\ Aicha Sekhari \\ University of Lyon 2 \\ (aicha.sekhari@univ-lyon2.fr)
}

Nowadays, companies implemented multiple Management System Standards (MSSs) to improve organizational performance in quality, security and environment functions. However, there is no unify integration standard to use, that's why companies use different approaches in order to manage quality, security and environment (QSE) integration. The first aim of this article is to analyze the extent to which QSE Management systems are really integrated and which methodologies are used by enterprises, the second aim is to analyze the impact of this integration on process performance. To this end, an empirical study was carried out on 100 companies in Morocco.

Keywords : Integrated Management System (IMS), Quality, Integration Level, Security, Environment, Process Performance

\section{Introduction}

The ever-increasing tendency of the International Organization for Standardization to publish new management systems has driven many organizations to multiple certification implementing two or more systems with different scopes, such as quality management, environmental management, occupational health and safety, etc, as confirmed by Wiengarten et al., (2017).

The structural similarities between these systems have prompted organizations to try to unify them into a single system, instead of implementing them separately, according to Pano. T (2018).

In fact, although integration and IMSs have been studied in detail from theoretical point of view, there has been very little related empirical study. However, these researches do not explicitly study the relation between the integration of MSs and the enterprises efficiency, in other words what is the impact of the integration of QSE management systems on the processes performance? Also, is the approach used for integration influence the processes performance?

The main aim of this paper is to provide an empirical response to these questions. So, we will at first, present the various theoretical approaches of the integrated management system quality, security, and environment. In a second step, we will present an empirical study realised on 100 Moroccan companies. 


\section{Literature Review on QSE Integration Management System}

Karapetrovic \& Willborn, (1998); Beckmerhagen, Berg, Karapetrovic, and Willborn, (2003) defined an Integrated MS (IMS) as a 'set of interconnected processes that share a pool of human, information, material, infrastructure, and financial resources in order to achieve a composite of goals related to the satisfaction of a variety of stakeholders'.

Organisations may have multiple MSs implemented and has the option to manage them either separately or in an integrated manner as tested by Bernardo. M, Gotzamani. K, Vouzas. F \& Casadesus. M (2016).

In the literature, Bernando (2016) attested that the process of integrating multiple MSs can be divided into four main aspects namely integration strategy, integration methodology, integration level and systems' auditing integration.

In this paper, we will focuse on two aspects of integration: methodology and level or degree of integration; and their relation on processes 'performance.

\subsection{QSE Integration Approaches}

Several approaches of QSE integration allow unifying the three-management systems quality, safety and environment, many authors have suggested various integration methodologies

First, we find the Plan, Do, Check, Act (PDCA) logic which constitute one of the pillars of all management systems and allows them to be dynamic instead of static, and constantly improving. This finding is also confirmed by Savino and Mazza (2014), who explained how integrated environmental and quality continuous improvement can occur through a practical implementation of PDCA cycle.

Secondly, the risk management as it has been used for OHSAS 18001. Indeed, the approach to risk assessment represents a major axis of similarities found in the logic of integration of management systems. Leaders must manage and foremost assess. To do this, they must be identified and minimized. Any economic activity generates risks.

According to Labodova. A (2004), this integration methodology based on risk management is done in seven stages.

In this case, Bennouna. F, Sekhari. A, and Amegouz. D (2014) proposed an integration methodology based on the Quality Function Deployment (QFD) and risk approaches.

Thirdly, a survey conducted in Spain by Simon. A, Karapetrovic. S, Casadesus. M (2012) shows that the analysis of common elements of standards and process map are the most common methods used during the integration process.

In addition, we find the notion of generic processes, a new concept that supports and facilitates the integration of systems, as confirmed by Harmand and Ekcl (2007).This model supports various management systems related to quality, environment and safety. This model provides the company with sufficient flexibility to incorporate with different types of requirements in a single system. The generic processes as defined by Eckl (2004):

- Responsibility, Commitment and Leadership;

- Conception / planning;

- Resource management; 
- Realization;

- Measures, Audits and Reviews;

- Analyses / studies;

- Corrective and preventive improvement.

Also, Puri. S (1996) proposed a "ten phase road map for developing and implementing an integrated EMS/Total Quality Management system', Karapetrovic and Willborn (1998) discussed a system based approach with seven integration steps, Wright (2000) presents "the key elements" to integrate MSs based on ISO 14001 (five steps) and OHSAS 18001 (four steps) with ISO 9001, and Zeng et al. (2006), in an empirical research project in China, proposed a three-level "synergetic model for implementing an IMS',

\subsection{Integration Level}

Another point is the degree of integration of each process because there is no single way to integrate QSE process for all companies, but each company has its specificity and its characteristics. That is why we have found through our reading that there are several levels or degrees of integration.

Wilkinson and Dale (1999) describe a four-level model. The first level "applies to individual MSs, where the system is integrated into every function and activity" of the organization. The second level is a combination of "systems based on the identified linkages between MSs". The third level "involves integrating selected parts" of MSs "with other certificated systems, but without using identified linkages". The fourth level "is to integrate both certificated and uncertificated systems with the overall MS", with the policies and objectives "aligned to and supporting the overall strategy, policy and objectives of the business.',

Seghezzi (1997) describes three "different paths to system integration: adding, merging and integration." For "addition", the sub-systems for quality, environment and safety, are kept separate «Described in separate documents." For "fusion" work instructions are fully integrated, but not procedures and the manual "total system is created, but the subsystem is still visible." For "integration", companies can choose or develop a generic management system as their general system and include all subsystems. "

Kirkby (2002) proposes an approach that has three main models of integrated management systems. The first level is "separation" where the systems are independent; the second is "alignment" in which different systems may have common points such as internal audit and management review. The third level is the "integration" which combines all the systems into one common system.

For Karapetrovic (2002), there are three degrees of integration: those which have integrated only documentation, those which have aligned processes, objectives, and resources and finally those which have integrated all parts of management systems in a single management system.

Bernardo et al. (2012a) argue that those organizations that implement QMS and EMS simultaneously achieve higher levels of integration, while those implementing more MSs separately achieve lower levels of integration.

\subsection{IMS and Process' Performance}

Many authors studied the link between IMS and companies' performance. Bernardo 
et al. (2012) attested that Incorporation of objectives, resources, procedures, and strategic goals of a firm can be a good way to tackle problems, create competitive advantage and sustainable development. Also, Bernardo et al. (2015) conducted a literature review in the Web of Science, Science Direct, Scopus and Emerald databases to identify the benefits and difficulties arising from implementation and use of IMSs. In all, 18 empirical articles were analyzed and the results showed that the companies which integrate their management systems have obtained more benefits when compared with companies that choose to manage the systems separately.

In this case, the correlation between safety, environment and improvement of productivity has been studied by Savino and Mazza (2014) and Savino et al., 2017). In addition, Savino and Batbaatar (2015) confirmed that the understanding that productivity can be increased with better health and safety conditions and with the consideration of social issues has been linked to production and operational performances as well as to the health, safety and social issues of workers and employees. Some investigations were also directed towards safety and ergonomics issues (Savino and Batbataar, 2015; Savino et al., 2017), exploring how safety and working environment may influence production performances.

More recently, Bernardo et al. (2018) confirmed that top management consider integration as a strategic toll to gain competitive advantage.

Thus, the idea of forming integrated MSs has become a strategic decision and has attracted the attention of both practitioners and scholars because of its relevance in achieving competitiveness and sustainability as conclude by (Rebelo et al., 2016).

The main conclusion that can be drawn from this literature review is that the question of integration has been approached by several authors using different methods. Also, level of QSE integration were related in different works and discussed from different point of view. In addition, several authors studied benefits of integration of quality, safety and environment in one management system and confirmed the positive impact of integration on competitiveness. However, the questions of the impact of QSE integration on process' performance and which methodology of integration impact more efficiency and performance, especially in Moroccan companies, are not enough studied. So, we are going to present an empirical study that can contribute to answer to these questions.

\section{Methodology}

A questionnaire was sent to 100 companies that can have or not an ISO certificate. These companies are located in Morocco. This study was carried out over 8 months to allow collecting maximum data.

The questionnaire was addressed to the MS managers of the organization. It was divided in three sections:

- Certificates that enterprises have or not;

- Integration approaches used by enterprises and reasons that push them to integrate management system;

- Impact of integration on processes' performance.

We will present and interpret the various information collected in the survey in order to respond the questions mentioned in introduction. 


\section{Results}

To know the position of Moroccan companies relative to integrated management and their degree of commitment to an integrated management system QSE, we conducted an exploratory study of Moroccan companies and multinationals companies in Morocco. A questionnaire was sent to small, medium and large companies in different sectors of activity.

The objective of this study is to determine the existing management systems in companies, analyze the willingness of companies to move towards an IMS or not and to study integration approaches used by enterprises and the impact of QSE integration on process' performance.

\subsection{Descriptive Analysis}

\subsubsection{Certifications}

The first result of this survey shows that over 100 Moroccan companies who responded so far, $90 \%$ of them are for the establishment of a QSE integrated management system, knowing that $92 \%$ of the companies surveyed have opted for at least one certification or they consider starting another one.

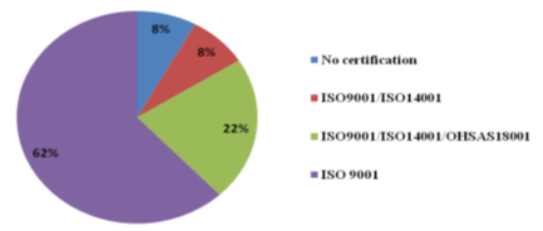

Figure 1 Certifications of the Companies

The first axis we have analyzed is certifications obtained by these companies. We can see through the figure above that more than $62 \%$ of companies are ISO 9001 certified with $22 \%$ who received three certifications ISO 9001, ISO14001 and OHSAS 18001, as we can see in the chart above.

These results reflect necessarily the interest of companies for quality, safety and environmental aspects.

An integrated management system will allow significant time savings in terms of development, especially when we have multiple management systems. According to the results of the survey, a certification project requires an average of 18 months for each system.

\subsubsection{Integration Approaches}

The second axis allows us to analyze which integration approaches are more used by companies.

As explained in literature review, there are many integration methodologies. In this case, we asked companies about approaches that are used.

The figure below shows that over $45 \%$ of respondents used the Plan, Do, Check and Act principle (PDCA) as an integration methodology. In the second position, we find risk management as integration approach. Thirdly, $20 \%$ of respondents attested that they use synergic models based on standards, especially ISO standards (ISO 9001, ISO 14001 and OHSAS 18001) as integration approach. 


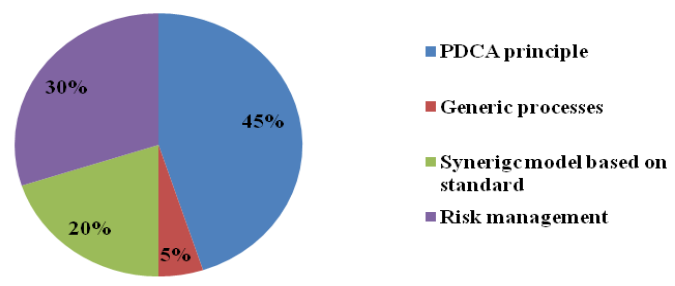

Figure 2 Integration Approaches

\subsubsection{Integration Level of Processes}

We started by asking companies about integration level of processes in order to identify processes that have higher integration levels. We asked MS managers to affect an integration degree to the most important processes, by using this classification (Table1):

Table 1 Integration Level

\begin{tabular}{|l|l|}
\hline \multicolumn{1}{|c|}{$\begin{array}{c}\text { Integration } \\
\text { level }\end{array}$} & \multicolumn{1}{c|}{ Processes } \\
\hline Fully integration & $\begin{array}{l}\text { Processes that are totally managed by considering the three aspects quality, } \\
\text { security and environment. }\end{array}$ \\
\hline $\begin{array}{l}\text { Partially } \\
\text { integration }\end{array}$ & Processes that are partially integrated \\
\hline No integration & $\begin{array}{l}\text { Processes which don't consider integration and quality, security and } \\
\text { environment are managed separately. }\end{array}$ \\
\hline
\end{tabular}

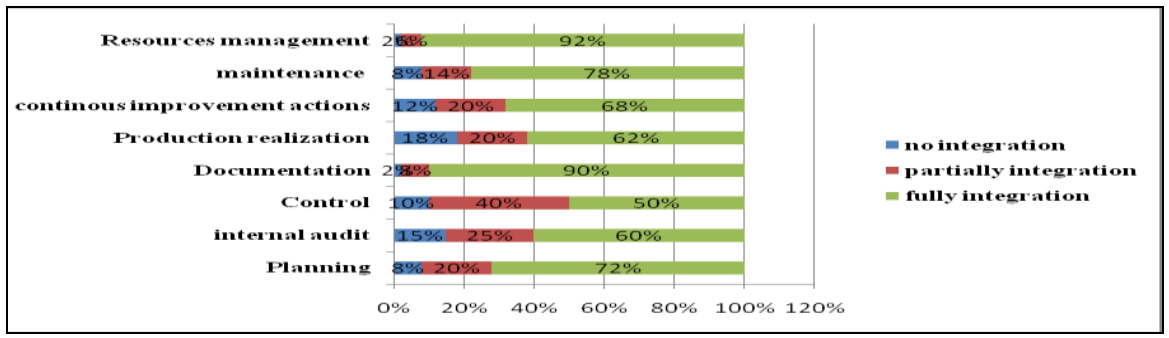

Figure 3 Integration Level of Processes

The results presented in Figure 3, show that the majority of enterprises use fully integration to manage "documentation" (90\% of entreprises) and "Ressources management" (92\%) processes. Managers justified this choice by many reasons such as saving time, avoid redudancy especially in documentation process,etc. Reasons of integration are more detailed in the next paragraph.

\subsection{Correspondence Analysis: Linking Integration Level with Process Performance}

In order to establish the correspondance between impact of integration and processes' performance, we asked managers about performance of the processes studied previously. 
The performance was studied by using the Key performance indicator (KPI) that evaluate the success at reaching the main target of the process.

In order to facilitate the questionnaire analysis, we classify process performance into three categories:

- High performance: for processes that reach more than $70 \%$ of their main goal.

- Medium perfomance: for processes that reach more than $40 \%$ of their main goal and less than $70 \%$.

- Low performance: for processes that reach less than $40 \%$ of their main goal.

- The results presented in Figure 4 show the percentage of companies opting for high, medium or low performance for each studied process.

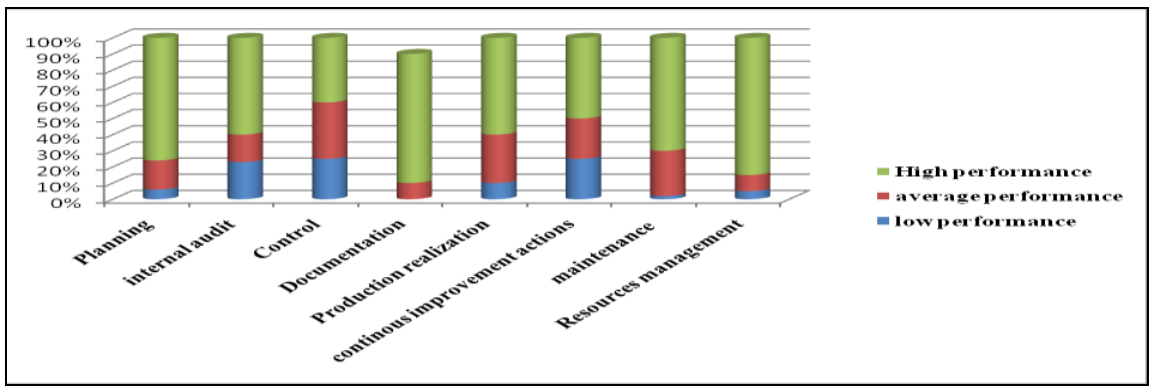

Figure 4 Performance of Processes

We observed that $80 \%$ of enterprises attested that "Documentation process" have a high performance, also $85 \%$ of them confirmed that "Resources Management process" have also high performance.

In order to establish the link between processes' performance and integration level, we studied the proportionality of these two data by calculating the coefficient of proportionality (P.C.) that is the ratio between the percentage of enterprises that answer 'high performance' on the percentage of enterprises that respond 'fully integration' for each process.

Considering that more than $50 \%$ of enterprises answer 'fully integration' for all processes; we calculate the proportionality coefficient (P.C.) for these enterprises.

Table 2 Proportionality Coefficient (P.C.)

\begin{tabular}{|l|c|c|c|}
\hline \multicolumn{1}{|c|}{ Process } & $\begin{array}{c}\text { \% enterprises } \\
\text { High performance }\end{array}$ & \% enterprises fully integration & P.C. \\
\hline Planning & $76 \%$ & $72 \%$ & $\mathbf{1 , 0 6}$ \\
\hline Internal audit & $60 \%$ & $60 \%$ & $\mathbf{1 , 0 0}$ \\
\hline Control & $40 \%$ & $50 \%$ & $\mathbf{0 , 9 0}$ \\
\hline Documentation & $80 \%$ & $90 \%$ & $\mathbf{0 , 8 9}$ \\
\hline Production realization & $60 \%$ & $62 \%$ & $\mathbf{0 , 9 7}$ \\
\hline Continous improvement & $50 \%$ & $68 \%$ & $\mathbf{0 , 7 4}$ \\
\hline Maintenance & $70 \%$ & $78 \%$ & $\mathbf{0 , 9 0}$ \\
\hline Resources management & $85 \%$ & $92 \%$ & $\mathbf{0 , 9 2}$ \\
\hline
\end{tabular}


We can observe from the results presented in Table 2 that for all processes $0.74 \leq \mathrm{P} . \mathrm{C} \leq 1.06$ and for 7 processes out of 8 , the P.C is higher than 0.8 . This result proves that for the majority of enterprises (more than $50 \%$ ), high performance is proportional to fully integration, because percentage of companies that answer 'fully integration' is almost the same percentage that answer 'High performance', for all processes.

This result shows that as long as the integration level is high, the processes' performance is also high.

We can see this proportionality in the Figure 5 that presents the correspondence between fully integration and high performance of process.

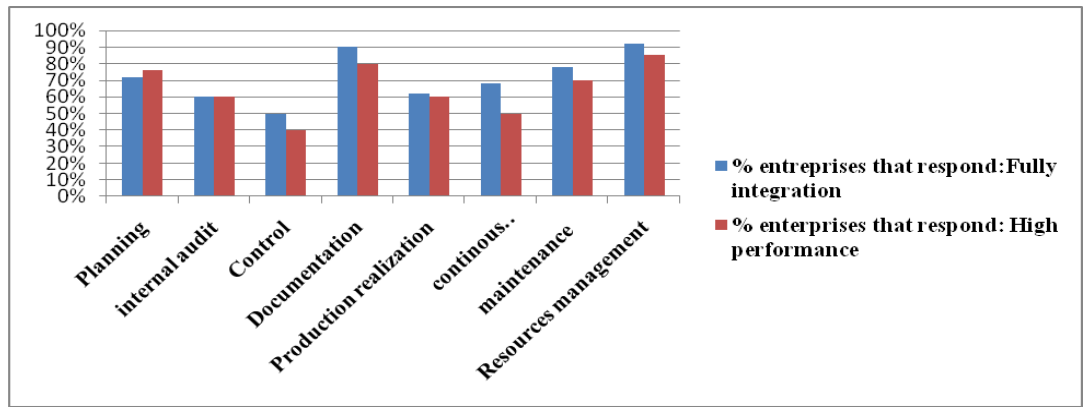

Figure 5 Correspondance between Integration and Performance

In order to deepen our analysis, we asked managers about the integration methodology used, more than $75 \%$ of them attested that PDCA method (45\%) and risk management $(30 \%)$ as presented in Figure 2, are the main approaches used in order to integrate and manage these processes. This respond explained the high performance of these processes.

The main conclusion that can be drawn from these results is that QSE integration impact processes' performance because the integration approaches used permit at the same time, to integrate quality, security and environments aspects and to improve processes continuously. Schema 1 synthesizes this conclusion:

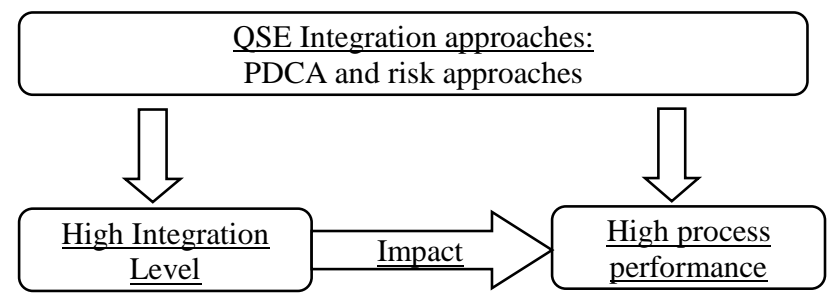

Schema 1 Correlation between Integration and Performance

This conclusion can be justified by the benefits of integration that impact seriously many key performance indicators. For this reason, we asked managers about reasons and benefits of QSE integration. 
We presented the main benefits mentioned by asked managers in an "Ishikawa diagram" in order to classify the reasons that are at the same time benefits, on the five categories of Ishikawa (5M): Method; Ressources and documents; Man; Machine; Environment.

The choice of this diagram can be justified by the fact that Ishikawa diagram application areas are continuously expanding. For example, nowadays the method is also being applied in the medical field (Kam cheong, 2011). So, we develop an ishikawa diagram in order to show that the $5 \mathrm{M}$ of processes are concerned by integration benefits.

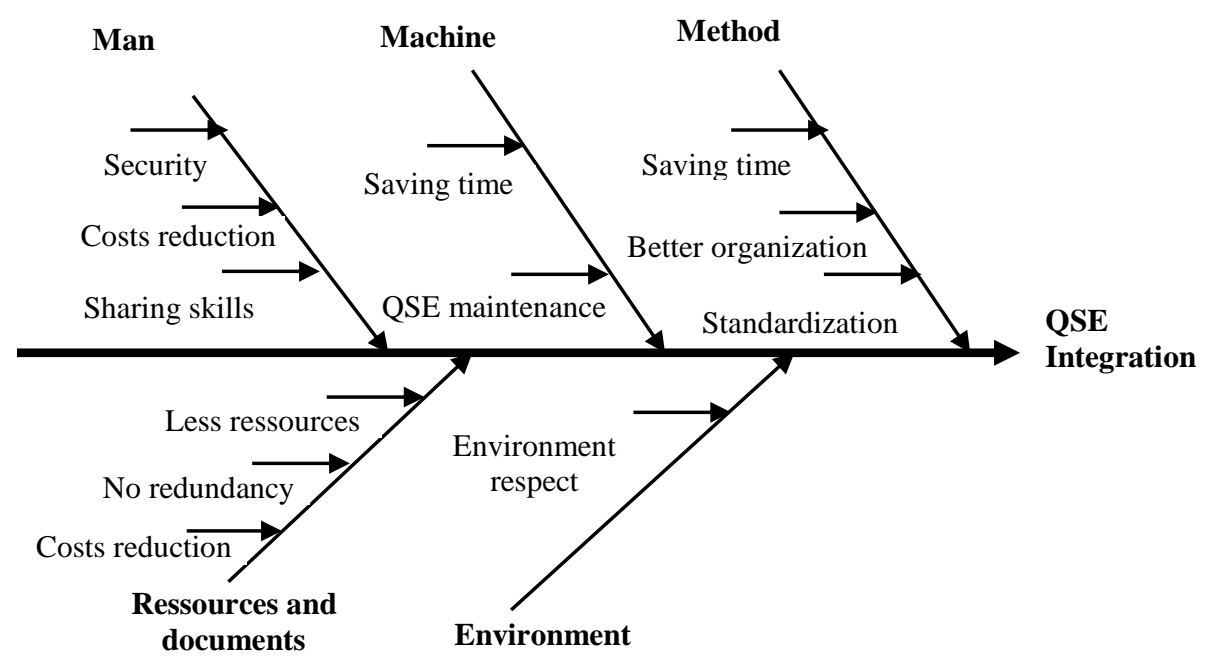

Schema 2 Ishikawa Diagram

This diagram (Schema2) synthesizes reasons that push asked enterprises to integrate QSE management systems.

We can observe that QSE integration benefits impact the $5 \mathrm{M}$ of processes, which can explain the impact on process performance.

In terms of method, for example, asked managers explained that is more complex to manage MSs separately, because internal audits, management reviews, etc, need a lot of time, if non-integrated.

Documentation and methods are ones of the aspects that are more affected by integration, because of redundancy and bureaucracy that increased if management systems are managed separately.

Also, for machine maintenance, asked managers attested that it is better to manage the maintenance by taking into account the three Management systems in order to save time and costs. This kind of maintenance improves security of operators.

As confirmed by Zeng et al. (2007); Griffith and Bhutto (2008); Almeida et al. (2014); Poltronieri et al. (2018), economic benefits can also arise from better allocation and utilization of financial, material or informational resources.

These results are in line with the results of Simon, M. Bernardo, S. Karapetrovic, M. Casadesus (2013) and the conclusions of Ribeiro.F, Santos.G, Ferreira.M, Silva.R 
(2017), where it was concluded that integration of MSs promotes synergies and costs savings.

\section{Discussion}

From the results obtained, we can conclude that there is a great number of Moroccan companies which had already integrated their MSs at various levels.

The main conclusion that can be highlighted is the proportionality between high processes performance and high integration level (fully integration) that we observed for the majority of enterprises.

Also, there is one element that was studied in our research, which differs from what we found in literature review, the impact of QSE integration approaches used by enterprises on process performance. The results showed that the majority of enterprises use PDCA and risk management as integration approaches. This can be justified by the fact that quality management and risk management are largely interrelated (Samani, 2017). The recent consideration looks at quality management and risk management as two important interrelated key performance indicators (KPIs) for performance management (Arena \& Arnaboldi, 2014; Popescu \& Dascalu, 2011).

In addition, we observed that, it's the integration methodology used in processes that have a high integration level, that influence their performance. This conclusion was confirmed by $75 \%$ of asked managers.

These findings explained the multiple benefits of QSE integration, that we classified in an "Ishikawa Diagram" in order to show that integration impact positively the $5 \mathrm{M}$ of processes which improve their performance.

According to the majority of participants' companies, the integration of MSs helped them in becoming more efficient and take advantage of the potential synergies of the MSs, as mentioned in other researches (Bernardo et al. (2015); Karapetrovic \& Casadesu's (2009); Karapetrovic \& Willborn (1998); Zeng et al (2007)).

On the one hand, this empirical study explains the impact of integration on process performance and MSs'efficiency observed in the survey presented.

On the other hand, it allowed understanding that QSE integration can be used as a tool to improve processes' performance and key indicators of quality, security and environment, especially if the integration methodology used, is based on PDCA and risk management.

\section{Conclusions}

In this research, we noticed that several companies are spontaneously moving towards the integration of management systems, but not all of them are aware of impact of this integration on the processes' performance. In addition, each company approaches this integration with a different method. However, we found in this study that integration has a direct influence on performance indicators and that the choice of approach also impacts the processes' performance. In this case, this study can encourage companies to move towards an integrated management system by giving importance to the method used.

So, from this study, we made many conclusions: 
- Many integration approaches are used by Moroccans companies.

- The integration approach used impact the level of performance.

- The integration of processes is done on various levels.

- The level of integration impact processes "performance.

Finally, the main conclusion that can be highlighted from the findings, is that quality, security and environment integration have become necessity because it impacts efficiency and performance of companies, whatever the MSs are certified or not. The added value of this paper was the establishment of correlations between integration level, performance, and integration approaches used.

This study enables researchers and academicians to conduct future research in number of areas relevant to integrated management systems, integration approaches and performance.

As a perspective of this work, it would be interesting to compare the results obtained in Morocco with other countries in order to study the impact of social factor.

\section{References}

1. Almeida.J, Domingues.P, and P.Sampaio, (2014), "Different perspectives on management systems integration", Total Quality Management \& Business Excellence, Vol. 25 Nos 3-4, pp. 338-351.

2. Arena. M, \& Arnaboldi.M (2014) 'Risk and performance management: Are they easy partners? Management Research Review', 37, 152-166. doi:10.1108/MRR08-2012-0180.

3. Asif, M., Bruijn, E.J.D., Fisscher, O.A.M., Searcy, C., Steenhuis, H.-J., (2009), 'Process embedded design of integrated management systems.' International Journal of Quality and Reliability Management 26 (03), $261 \mathrm{e} 282$.

4. Asif, M., Fisscher, O.A.M., Joost de Bruijn, E., Pagell, M., (2010), 'An examination of strategies employed for the integration of management systems'. The TQM Journal 22 (6), 648e669.

5. Beckmerhagen, I., Berg, H., Karapetrovic, S., \& Willborn, W. (2003a), Integration of management systems: Focus on safety in the nuclear industry. International Journal of Quality \& Reliability Management, 20, 210-228.

6. Bennouna.F, Sekhari.A, Amegouz.D, (2014), 'A system of quality, security and environment integration based on QFD and reisk approaches' Intenartional Journal of operations and Quality Management, Volume 20, Number 3, pp. 101116.

7. Bernando.M, Casadesus.M, Karapetrovic.S, Heras.I (2012), 'Do integration difficulties influence management system integration levels?' Journal of Cleaner Production 21,23-33.

8. Bernardo, M., Casadesu's, M., Karapetrovic, S., \& Heras, I. (2012), 'Integration of standardized management systems: Does the implementation or der matter?' International Journal of Operations \& Production Management, 32, 291-307.

9. Bernardo, M., Simon, A., Tarı', J. J., \& Molina-Azorı'n, J. F. (2015), 'Benefits of management systems integration: A literature review'. Journal of Cleaner Production, 94, 260-267. 
10. Bernardo.M, Gotzamani.K, Vouzas.F \& Casadesus.M (2016),' A qualitative study on integrated management systems in a nonleading country in certifications', Total Quality Management \& Business Excellence, DOI: 10.1080/14783363.2016.1212652.

11. Bernardo.M, Gotzamani.K, Vouzas.F \& Casadesus.M(2016), 'A qualitative study on integrated management systems in a nonleading country in certifications', Total Quality Management \& Business Excellence, DOI: $10.1080 / 14783363.2016 .1212652$

12. Castka, P., Balzarova, M.A.,(2008), 'The impact of ISO 9000 and ISO 14000 on standardization of social responsibility e an inside perspective'. International Journal of Production Economics 113 (1), 74e87.

13. Danihelka P (2001), 'Subjective factors of cleaner production - parallel to risk perception?' Proceedings of 7th European Roundtable on Cleaner Production, pdf file on CD, 2-4 May, Lund, Sweden.

14. Domingues, J. P. T., Sampaio, P., \& Arezes, P. M. (2015a), 'Analysis of integrated management systems from various perspectives.' Total Quality Management \& Business Excellence, 26, 1311-1334.

15. Griffith, A. and Bhutto, K. (2008), "Improving environmental performance through integrated management systems (IMS) in the UK", Management of Environmental Quality: An International Journal, Vol. 19 No. 5, pp. 565-578.

16. Kam Cheong Wong (2011), 'Using an Ishikawa diagram as a tool to assist memory and retrieval of relevant medical cases from the medical literature', Journal of Medical Case Reports 2011, 5:120. http://www.jmedicalcasereports.com/content/5/1/120.

17. Karapetrovic S, Willborn, W (2018), Integration of quality and environmental management systems". TQM Magazine ;10(3):204-13.

18. Karapetrovic, S., \& Casadesu's, M. (2009), 'Implementing environmental with other standardized management systems: Scope, sequence. time and integration'. Journal of Cleaner Production, 17, 533-540.

19. Karapetrovic, S., \& Willborn, W. (1998a), 'Integration of quality and environmental management systems.' The TQM Magazine, 10, 204-213.

20. Karapetrovic, S., \& Willborn, W. (1998b), 'Integrated audit of management systems.'International Journal of Quality \& Reliability Management, 15, 694711.

21. Karapetrovic, S., Casadesus, M., Heras, I.,(2010), 'What happened to the ISO 9000 lustre? An eight-year study'. Total Quality Management \& Business Excellence 21 (3), 245e267.

22. Karapetrovic.S (2002) 'Strategies for the integration of management systems and standards', TQM Magazine; 14(1):61-7.

23. Khanna, K.H., Laroiya, S.C., Sharma, D.D., (2010) 'Integrated management systems in Indian manufacturing organizations: some key findings from an empirical study'. The TQM Journal 22 (6), 670e686.

24. Kirkby.A (2002), 'The one-stop shop'. Qualityworld; January. p. 2-4.

25. Labodova.A (2004), 'Implementing integrated management systems using a risk analysis based approach', Journal of Cleaner Production 12, 571-580 
26. Lévêque. L, Mathieu. S, et Massé.J.P (2003), 'Outils d'autodiagnostic pour la mise en place d'un management intégré : Qualité - sécurité - Environnement', Afnor Editions.

27. Merce.B, Casadesus.M, Karapetrovic. S (2009), 'Iñ aki Heras. How integrated are environmental, quality and other standardized management systems? An empirical study'. Journal of Cleaner Production 17, 742-750.

28. Metin.C (2009), 'A hybrid design methodology for structuring an Integrated Environmental Management System (IEMS) for shipping business', Journal of Environmental Management 90, 1469-1475.

29. Nawaz S., Della Selva V., Savino M. M. (2016), 'Extensive Literature Review to assess the sustainability drivers of production performances using a resourcebased view and contingency analysis', Journal of Cleaner Production 204 (2018), pp. 744-752.

30. Ouzrout Y, Apolloni S, Savino M (2008), 'Product quality pointers for small lots production: a new driver for Quality Management Systems'. International Journal of Product Development, vol. 5, pp. 199-211

31. Panos T. Chountalas, Filippos A. Tepaskoualos, (2018) "Selective integration of management systems: a case study in the construction industry", The TQM Journal, https://doi.org/10.1108/TQM-03-2018-0028.

32. Poltronieri, C.F., Gerolamo, M.C., Dias, T.C.M. and Carpinetti, L.C.R. (2018), "Instrument for evaluating IMS and sustainable performance", International Journal of Quality \& Reliability Management, Vol. 35 No. 2, pp. 373-386.

33. Popescu, M., \& Dascalu, A. (2011) 'Considerations on integrating risk and quality management'. Dynamics, 2, 49-54.

34. Puri S (1996), 'Stepping up to ISO 14000: integrating environmental quality with ISO 9000 and TQM'. Portland, USA: Productivity Press.

35. Rebelo, M. F., Santos, G., \& Silva, R. (2016). 'Integration of management systems: Towards a sustained success and development of organizations', Journal of Cleaner Production, 127, 96-111.

36. Ribeiro.F, Santos.G, Ferreira.M, Silva.R (2017), 'Integrated management systems: Trends for Portugal 2025 horizon models for capacity optimization in Industry 4'. Manufacturing Engineering Society International Conference 2017, MESIC 2017, 28-30 June 2017.

37. Samani.M.A, Ismail.N, Leman.Z \& Zulkifli.N (2017), 'Development of a conceptual model for risk-based quality management system', Total Quality Management \& Business Excellence, DOI: 10.1080/14783363.2017.1310617.

38. Savino M., Brun A., Xiang C. (2017) 'A fuzzy-based multi-stage quality control under the ISO9001:2015 requirements', European J. Industrial Engineering, Vol. 11, No. 1.

39. Savino, M.M., Batbaatar, E. (2015), 'Investigating the resources for Integrated Management Systems within resource-based and contingency perspective in manufacturing firms', Journal of Cleaner Production, vol. 104, pp. 392-402.

40. Savino, M.M., Shafiq, M., (2018), 'An extensive study to assess the sustainability drivers of production performances using a resource-based view and contingency analysis', Journal of Cleaner Production 204 (2018), pp. 744752. 
41. Savino.M and Mazza.A (2014), 'Toward Environmental and Quality Sustainability: An Integrated Approach for Continuous Improvement', IEEE Transactions on engineering management, 61 (1), 6675831, pp. 171-181.

42. Seghezzi.H (1997), 'Business concept redesign' Total Quality Management, $8(2 \& 3), 36-43$.

43. Seklouli.A and Gien.D (2001), 'Decision-Making Support Based on QFD.To Perform System Design Quality, CIMA'2001', International ICSC-NAISO Congress On Computational Intelligence: Methods and Applications; June 1922, The University of Wales; Bangor, UK.

44. Simon, M. Bernardo, S. Karapetrovic, M. Casadesus (2013), Total Qual. Manag. Bus. Excell. 24 (3-4) 294-309.

45. Simon.A, Bernardo.M, Karapetrovic.S, Casadesus.M (2013), Total Qual. Manag. Bus. Excell. 24 (3-4) 294-309.

46. Simon.A, Karapetrovic.S, Casadesus. M (2012), 'Evolution of Integrated Management System in Spanish firms', Journal of Cleaner Production 23, 1819.

47. Vacharapoom. B, Sdhabhon .B (2010), 'An integrated safety management with construction management using 4D CAD model', Safety Science 48, 395-403.

48. Vigo, Spain. Salomone, R., (2008). 'Integrated management systems: experiences in Italian organizations', Journal of Cleaner Production 16 (16), $1786 \mathrm{e} 1806$.

49. Wiengarten, F., Humphreys, P., Onofrei, G. and Fynes, B. (2017), "The adoption of multiple certification standards: perceived performance implications of quality, environmental and health \& safety certifications", Production Planning \& Control, Vol. 28 No. 2, pp. 131-141.

50. Wilkinson.G, Dale. B (1999), 'Integration of quality, environment and health and safety management systems: an examination of key issues', Proceedings of the Institution of Mechanical Engineers, Part B, Journal of Engineering Manufacture; 213(3):275-83.

51. Wright T. IMS (2000) 'three into one will go!: the advantages of a single integrated quality, health and safety, and environmental management system'. The Quality Assurance Journal; 4(3):137-142.

52. Zeng S, Shi J, Lou G. (2006) 'A synergetic model for implementing an integrated management system: an empirical study in China'. Journal of Cleaner Production; 15(18):1760-7.

53. Zeng, S., Shi, J., \& Lou, G. (2007). 'A synergetic model for implementing an integrated management system: An empirical study in China'. Journal of Cleaner Production, 15, 1760-1767.

\section{About Our Authors}

Fatima Bennouna is, currently Assistant Professor in the industrial engineering department at National School of Applied Sciences of Fez (ENSAF) in USMBA University of Fez, Morocco. In 2015, She obtained her Ph.D in industrial engineering from USMBA University of Fez. She received her Engineering Degree in industrial engineering in 2008 from Mohammadia School of Mohammad V University in Rabat, Morocco. Fatima's current research covers the field of 
integrated management systems, Product Lifecycle Management (PLM), Management Executing system (MES).

Driss Amegouz is currently Professor and Head of Department "Mechanical, Productive and Industrial Maintenance Engineering" at the FES Higher School of Technology (SMBA-EST University of Fez). Driss Current research covers the field of management life cycle and management of the supply chain. He is on the steering committee of the research laboratory in Industrial Technologies and Services. (2002) Ph.D. "Mechanical CAD/CAM" (university of SMBA-FST of Fez) (1995) High-depth study "DEA" Automated Production of Speciality (University of Paris-6- ENS Cachan France). (1992) Engineer awarded a diploma "Mechanical Engineering and Production"(ENIM of Metz FRANCE). (1989)University Technology Diploma (DUT) in Mechanical engineering and industrial automation, (university-EST FEZ).

Aicha Sekhari Seklouli is currently associate professor in Business process and data management at University Lumière Lyon2. She is a Director of RTI "Research, Innovation and Transfer Pole" institute of technology Lumière Lyon2. Dr Sekhari Aicha is conducting research and publication on Product Life cycle Management and Supply Chain Management. She is currently coordinating various EU and International Projects. She received her Engineering Degree in Electronics from University of SETIF in Algeria. After three years of industrial experience, she joined INSA school of Lyon for her MSc. degree and obtained her Ph.D in Production System from University of Clermond Ferrand, France. 